\title{
DENTRO OU FORA DA ESCOLA?
}

\author{
Maria Lúcia de Souza Barros Pupo
}

A multiplicação dos protagonistas da cena que presenciamos na atualidade, como não poderia deixar de ser, vem repercutindo diretamente na formação na Licenciatura em Artes Cênicas oferecida pela Escola de Comunicações e Artes da Universidade de São Paulo.

Se em seus primeiros tempos - lá se vão mais de três décadas - o campo da licenciatura visava exclusivamente ao ensino do teatro dentro do sistema educacional, hoje a situação é bem distinta. Demandas de entidades as mais variadas, tanto ligadas à sociedade civil como as ONGs, quanto instituições vinculadas ao poder público na área da cultura como é o caso de centros culturais, além de setores da área da saúde, constituem algumas das múltiplas esferas nas quais processos de criação em teatro - e, de modo mais abrangente, nas artes da cena - revelam uma área em plena expansão.

Índice eloqüente das transformações pelas quais o teatro vem passando entre nós, essa diversificação dos contextos nos quais ele ocorre certamente revela uma bem-vinda ampliação dos segmentos da população que têm acesso, hoje, à realização e à fruição teatral. Certamente é necessário muita cautela ao tratar essa expansão quantitativa, se levarmos em conta a escala da periferia das metrópoles brasileiras, mas é inegável que estamos fazendo referência a um fenômeno tangível, digno de análise cuidadosa.

Os exemplos mencionados acima dizem respeito a processos de conhecimento oriundos de experiências teatrais - envolvendo pessoas na qualidade de atuantes ou de espectadores - que se inserem em uma noção 
Urdimento

ampla de educação, baseada no princípio de que as ações interativas entre os indivíduos promovem a construção de saberes. Em outras palavras, estamos falando em modalidades de educação não formal, campo no qual a pesquisa em pedagogia do teatro vem fazendo avanços consideráveis entre nós.

O reverso da moeda, ou seja, a área da educação dita formal, apresenta um panorama de outra natureza. Como é sabido, a instituição escolar, coração do projeto democrático, não vem recebendo do poder público no Brasil a atenção merecida. Em meio às profundas transformação sociais que ora atravessamos no campo do trabalho, da organização familiar, das comunicações, a escola sobrevive em meio a perplexidades, sobressaltos e impasses. Se no campo das atividades levadas a efeito em caráter extra-curricular dentro de escolas públicas e particulares há exemplos de práticas teatrais bastante interessantes, eles são menos freqüentes quando analisamos os casos de experiências teatrais dentro do currículo escolar, o que, evidentemente, pode ser explicado pelas dificuldades mais amplas hoje inerentes à escola, principalmente pública, no Brasil. Temos aí configurado um quadro que certamente demanda atenção especial dos responsáveis pela formação de professores de artes cênicas, assim como daqueles que atuam nas demais licenciaturas no âmbito da universidade como um todo.

A mesma perspectiva de fazer da atividade cênica um dos vetores da educação denominada não formal vem ocupando o horizonte de vários grupos de teatro marcados pela preocupação com o caráter coletivo dos processos de criação.

Em Belo Horizonte o Galpão implantou no espaço de um antigo cinema o Galpão Cine Horto, desdobramento das perspectivas estéticas do conhecido grupo. Trata-se de um núcleo pedagógico que oferece cursos livres e oficinas de teatro para iniciantes, sejam crianças, jovens ou adultos, interessados em aprender teatro. Em Porto Alegre o Oi nóis aqui traveiz se atribuiu uma relevante função pedagógica ao criar uma escola na periferia da cidade, também voltada a um trabalho teatral com iniciantes, importante eixo da função social almejada pelo grupo.

Na capital paulista o Programa Municipal de Fomento ao Teatro para a Cidade de São Paulo, fruto da atuação de grupos e coletivos teatrais, constitui, ao mesmo tempo, poderoso apoio para a sua consolidação. Tendo em vista a sustentação de projetos continuados de pesquisa teatral, assim como um melhor acesso da população a essas realizações, o Fomento seleciona duas vezes por ano propostas de criação que revelam uma concepção do trabalho teatral enquanto ação cultural pública. Um exame preliminar do conjunto de

${ }^{1} 0$ termo aparece no texto da Lei.

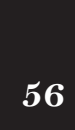
projetos contemplados desde 2002 - cerca de duzentos - revela interessantes modalidades de "contrapartida social" ${ }^{1}$ propostas pelos coletivos. Entre eles 
podemos destacar a ocupação e reforma de espaços abandonados; a ação em rede, implicando tessitura de vínculos e parcerias com escolas, centros culturais, entidades de bairro; a oferta de oficinas teatrais à população; a organização de encontros visando à formação de espectadores, além da documentação dos próprios processos de criação dos grupos beneficiados com o apoio público.

Os exemplos mostram um quadro singular: coletivos teatrais, revelando uma notável capacidade de intervenção na vida social, aliam experimentação, pesquisa e atuação pública, revelando seu compromisso com uma ação cultural que consagra campos de atuação efetivos, aquém e além do momento da representação propriamente dito. $\mathrm{O}$ teatro transborda das margens que até há pouco pareciam conter o seu percurso.

Antigos papéis cristalizados se embaralham, dando origem a vínculos inesperados entre o fazer artístico e a preocupação com a cidadania. Modalidades de educação não formal são desenvolvidas junto ao público das metrópoles pelos coletivos teatrais, comprometidos com um debate de caráter ativo em torno da função social do teatro. Limites estáticos e arbitrários entre cultura e educação caem por terra.

Na perspectiva de chamar a atenção para os vínculos entre as esferas da formalidade e da não formalidade, e voltando agora para o âmbito do sistema educacional, gostaríamos de trazer à tona um aspecto da formação oferecida pela Licenciatura em Artes Cênicas na ECA-USP.

No último semestre da referida formação, os licenciandos organizam uma mostra na qual apresentam monografias de conclusão de curso resultantes de processos de aprendizagem teatral por eles conduzidos, acompanhadas, sempre que possível, de apresentações públicas vinculadas a esses processos.

Esse momento final é precedido pelo acompanhamento contínuo do estudante, em um caminho que vai desde a primeira versão do projeto ao qual se propõe, passa pelas dificuldades naturais de sua implantação e desenvolvimento e pelos impasses ligados à escritura, até chegar ao exame da monografia por um conjunto de docentes em sessões abertas ao público. Do ponto de vista dos estudantes às vésperas da conclusão do curso trata-se de ocasião especialmente rica, na qual eles encerram um ciclo de acompanhamento da trajetória dos colegas envolvidos com investigações sobre processos de aprendizagem em teatro.

Tendo em vista a diversidade dos contextos nos quais pode se dar hoje a atividade teatral, cada estudante tem autonomia para propor seu projeto no ambiente que lhe aprouver. Não apenas escolas de ensino básico, 


\section{Urdimento}

${ }^{2}$ Bianca Zanchetta e Priscilla Carbone. mas também parcerias com entidades as mais diversas, públicas e privadas e até mesmo o espaço da rua vêm sediando a atuação dos jovens formandos. São portanto múltiplos e diversificados os processos de aprendizagem teatral coordenados pelos estudantes. Em determinadas ocasiões esses processos se tornam objeto de tentativas de enquadramento por normas institucionais que tentam neutralizar o potencial transgressor do fazer teatral. Em outras circunstâncias, menos institucionalizadas, os processos em questão são encarados como desejável atividade simbólica que contribui para a ampliação do olhar sobre o mundo e recebidos calorosamente.

Dois exemplos provenientes da mostra apresentada pelo Departamento de Artes Cênicas em dezembro de 2007 ilustram a inserção de processos de aprendizagem teatral dentro das esferas formal e não-formal de educação.

O primeiro deles se refere à inesperada impossibilidade de atuação no terreno da educação formal, verificada por uma dupla de estudantes ${ }^{2}$. As alunas em questão, a partir de diretrizes iniciais apresentadas em um préprojeto - valer-se da leitura de imagens e da abordagem de textos - previram com bastante antecedência (em relação ao calendário que havíamos montado em conjunto) iniciar o contato com escolas públicas de ensino fundamental, visando a constituir um grupo de adolescentes interessados na experiência que gostariam de levar a efeito. Dificuldades de toda ordem, no entanto, constituíram obstáculos que acabaram se revelando intransponíveis para a implantação do projeto: encontros com responsáveis institucionais cancelados, protelados ou adiados, pretextos vinculados a problemas do espaço físico, impedimentos a priori atribuídos à organização de grupos de alunos em horários diferentes do habitual, acabaram tendo um efeito corrosivo sobre os planos das estudantes. Decepcionadas com o quadro diante do qual se deparavam, acabaram reorientando sua atuação para a coordenação de um processo junto a jovens no âmbito de uma oficina teatral de breve duração dentro da própria cidade universitária. Uma perversa conjugação de fatores, entre os quais supomos dificuldades de comunicação, inércia institucional, incompreensão da envergadura da experiência proposta - reveladores evidentemente de um sistema escolar atravessado por intensa crise - inviabilizaram uma atuação na escola, definida como prioritária pelas estudantes.

Um segundo exemplo, no sentido oposto ao anterior, ilustra o estabelecimento de vínculos promissores - verdadeiras "passarelas"- entre a instituição educativa e a ação cultural. Sandra Savóia Grasso Nascimento de Oliveira, em determinado momento de seu percurso como coordenadora de um grupo teatral de jovens de 17 a 20 anos no Colégio Equipe, em meio a experimentações a partir de Aquele que diz sim / Aquele que diz não de Brecht, 


\section{Urdimento}

formula junto com o grupo a interrogação que vai permear sua pesquisa: seria possível "desenvolver um processo de construção de conhecimentos acerca da mediação da recepção teatral com um grupo de jovens alunos-atores envolvidos com experimento com peça didática de Brecht e interessados em dialogar com seus espectadores?”3 A partir daí, juntos, Sandra e o grupo passam a apresentar sua encenação do texto brechtiano em uma perspectiva marcada pelo caráter lúdico, para platéias cada vez mais diferenciadas dos meios habitualmente freqüentados por eles. Simultaneamente concebiam, experimentavam e avaliavam modalidades de apropriação da cena que pudessem contribuir para que os espectadores se confrontassem, no nível do jogo teatral, com as questões relativas ao conformismo político e social formuladas por Brecht.

O fato de terem assistido coletivamente aos espetáculos Aldeotas e Vemvai, o Caminho dos Mortos, contribuiu para a tarefa à qual se propunham. A partir deles os participantes foram convidados a conceber procedimentos de caráter lúdico que viessem a mediar a recepção dessas encenações, em um exercício de aproximação gradativa com o tema da leitura da cena, central nas preocupações do grupo naquele momento.

Uma mescla de leituras sobre a peça didática de Brecht e sobre a formação do espectador teatral associou-se a apresentações voltadas para diferentes platéias: do próprio Colégio Equipe, de uma mostra de teatro no Colégio Santa Cruz, de assembléia de movimento de juventude, e de participantes de um encontro do Projeto de Teatro Vocacional da Prefeitura Municipal de São Paulo. Em cada uma dessas ocasiões os jovens portanto, além de atuar, coordenavam sessões de jogos teatrais cuidadosamente planejados, visando à apropriação da cena por parte dos espectadores. Entusiasmados com a perspectiva de realizar um "teatro pensante que faz as pessoas pensarem”, os alunos do ensino médio concluíram sua trajetória respondendo ao desafio que lhes pareceu o mais complexo: apresentaram seu trabalho e propuseram reflexão sobre a cena através de modalidades lúdicas a uma platéia de adolescentes da Escola Municipal Amorim Lima, pouco mais jovem do que eles mesmos. O processo de construção de conhecimentos vivido pelo grupo, portanto, partiu de um contexto de educação formal e ganhou corpo mediante desdobramentos na condução de processos em diferentes contextos de educação formal e não-formal.

Dentro da situação que tentamos esboçar muito brevemente, na qual a inserção social dos grupos de teatro, a expansão da ação cultural e os graves impasses da escola constituem uma paisagem cujos contornos - talvez ainda relativamente imprecisos - continuam a surpreender, podemos constatar desafios de nova envergadura.

3"Pulgas atrás de orelhas. A peça didática de Brecht e a mediação da recepção teatral: uma perspectiva pedagógica". Trabalho de Conclusão de Curso, Departamento de Artes Cênicas, ECA- USP. 2007, p. 6. 


\section{Urdimento}

${ }^{4}$ Cf. o trabalho realizado na Colombia por Antanas Mockus, "A cidade como uma grande escola", Porto Alegre, GEEMPA, 2005, assim como 0 do grupo de pesquisadores de Barcelona, coordenado por Carmen Gómez-Granell e Ignácio Vila, "A cidade como projeto educativo", Porto Alegre, Artmed, 2003.

${ }^{5}$ Carmen GómezGranell e Ignácio Vila (org.), "A cidade como projeto educativo", Porto Alegre, Artmed, 2003, p. 31.
Equipes interdisciplinares em países diversos ${ }^{4}$ vêm indicando a crescente necessidade da elaboração de um "pacto social" entre diferentes entidades, órgãos e instituições públicos e privados que se responsabilizem pela educação e pela formação do conjunto da sociedade. "A crise da escola não pode ser resolvida a partir do interior da própria escola" é sem dúvida uma afirmativa a ser examinada com atenção. Se a escola brasileira carece de sérias medidas a curto, médio e longo prazo para tentar superar seus graves impasses, a ação cultural também constitui hoje um campo imprescindível na formação dos cidadãos.

Ao se alimentar da reflexão gerada por essas novas modalidades de atuação e pelos desafios cada vez mais complexos que se nos apresentam em nosso momento histórico, o campo da Pedagogia do Teatro tende a se ampliar e a se consolidar. Certamente teríamos muito a ganhar se nos muros da escola da educação básica fossem cavadas brechas que abrissem passagem para concepções de trabalho teatral em sintonia com as recentes dinâmicas instauradas nos espaços urbanos das metrópoles. 